\title{
Clinical Potential of Regulatory T Cell Therapy in Liver Diseases: An Overview and Current Perspectives
}

\author{
Hannah C. Jeffery ${ }^{1 \dagger}$, Manjit Kaur Braitch ${ }^{1 \dagger}$, Solomon Brown ${ }^{1}$ and Ye Htun Oo ${ }^{1,2 *}$ \\ ${ }^{1}$ NIHR Biomedical Research Unit in Liver Diseases, Centre for Liver Research, Institute of Immunology and Immunotherapy, \\ University of Birmingham, Birmingham, UK, ${ }^{2}$ Liver and Hepatobiliary Unit, University Hospital NHS Foundation Trust, \\ Birmingham, UK
}

The increasing demand for liver transplantation and the decline in donor organs has highlighted the need for alternative novel therapies to prevent chronic active hepatitis, which eventually leads to liver cirrhosis and liver cancer. Liver histology of chronic hepatitis is composed of both effector and regulatory lymphocytes. The human liver contains different subsets of effector lymphocytes that are kept in check by a subpopulation of $T$ cells known as Regulatory $T$ cells (Treg). The balance of effector and regulatory

OPEN ACCESS

Edited by: Nurit Hollander,

Tel Aviv University, Israel

Reviewed by:

Paolo Puccetti,

University of Perugia, Italy

Duncan Howie,

University of Oxford, UK

*Correspondence:

Ye Htun Oo

Y.H.Oo@bham.ac.uk

${ }^{t}$ Hannah C. Jeffery and

Manjit Kaur Braitch

contributed equally.

Specialty section: This article was submitted to Immunotherapies and Vaccines,

a section of the journal

Frontiers in Immunology

Received: 12 July 2016

Accepted: 19 August 2016

Published: 06 September 2016

Citation:

Jeffery HC, Braitch MK, Brown S and Oo YH (2016) Clinical Potential

of Regulatory T Cell Therapy in

Liver Diseases: An Overview

and Current Perspectives.

Front. Immunol. 7:334.

doi: 10.3389/fimmu.2016.00334 lymphocytes generally determines the outcome of hepatic inflammation: resolution, fulminant hepatitis, or chronic active hepatitis. Thus, maintaining and adjusting this balance is crucial in immunological manipulation of liver diseases. One of the options to restore this balance is to enrich Treg in the liver disease patients. Advances in the knowledge of Treg biology and development of clinical grade isolation reagents, cell sorting equipment, and good manufacturing practice facilities have paved the way to apply Treg cells as a potential therapy to restore peripheral self-tolerance in autoimmune liver diseases (AILD), chronic rejection, and posttransplantation. Past and on-going studies have applied Treg in type-1 diabetes mellitus, systemic lupus erythematosus, graft versus host diseases, and solid organ transplantations. There have not been any new therapies for the AILD for more than three decades; thus, the clinical potential for the application of autologous Treg cell therapy to treat autoimmune liver disease is an attractive and novel option. However, it is fundamental to understand the deep immunology, genetic profiles, biology, homing behavior, and microenvironment of Treg before applying the cells to the patients.

Keywords: regulatory $\mathrm{T}$ cells, microenvironment, metabolites, microbes

Regulatory T cells (Treg) are critical regulators of immune tolerance (1). Regulatory activity among the $\mathrm{CD} 25^{+}$subclass of CD4 $4^{+} \mathrm{T}$ cells was first discovered in 1995 by Sakaguchi and colleagues via adoptive transfer studies. Depleting the $\mathrm{CD} 25^{+} \mathrm{CD} 4^{+} \mathrm{T}$ cells from a $\mathrm{T}$ cell inoculum increased the rate at which graft versus host disease (GVHD) and features of autoimmune diseases developed in the recipient strain (2). The immunosuppressive potential of these cells was solidified in the result that replacement of the $\mathrm{CD} 25^{+}$fraction of $\mathrm{CD} 4^{+} \mathrm{T}$ cells could limit autoimmune disease induction $(2,3) . \mathrm{CD} 4{ }^{+} \mathrm{CD} 25^{+} \mathrm{T}$ cells constitute $5-10 \%$ of peripheral $\mathrm{CD} 4 \mathrm{~T}$ cells in the blood, and they play a crucial role in maintaining immunologic self-tolerance by actively suppressing self-reactive lymphocytes (2). Treg development is controlled by FoxP3, which encodes the transcription factor that is genetically defective in an autoimmune and inflammatory syndrome in humans and mice $(4,5)$. IL-7 receptor, CD127 expression inversely correlates with FoxP3 and 
suppressive function of CD4 ${ }^{+}$Treg $(6,7)$; thus, Treg are currently defined as a subset of CD4 lymphocytes with the surface marker profile $\mathrm{CD} 4^{+} \mathrm{CD} 25^{+} \mathrm{CD} 127^{\text {low }}$ and which express the intracellular transcription factor FoxP3. Treg are classified into two simple and broad categories; thymic-derived Treg (previously known as naturally occurring Treg) and peripheral Treg (previously labeled as adaptive Treg) (8).

\section{PROFILE OF REGULATORY T CELLS IN LIVER DISEASES}

The majority of chronic active hepatitis is immune-mediated liver injury (9). Many investigators have reported Treg frequency variation in the peripheral blood in acute liver injury, chronic liver diseases, and liver cancer, but there are limited data on intrahepatic Treg. Reduction in $\mathrm{CD} 4{ }^{+} \mathrm{CD} 25^{\text {high }} \mathrm{CD} 127^{\text {low }}$ Treg frequency has been described in patients with alcoholic hepatitis (10). Progression from non-alcoholic fatty liver to non-alcoholic steatohepatitis is characterized by a higher frequency of Th17 cells in the liver and an increased ratio of Th17/resting CD $4{ }^{+} \mathrm{CD} 45 \mathrm{RA}^{+} \mathrm{CD} 25^{\text {high }}$ Treg in peripheral blood (11). We, and others, have reported that there is an increase in Treg frequency in parallel with effector immune cells in autoimmune liver diseases (AILD) (12-15). Treg also appear to play a role in the immunopathogenesis of primary biliary cholangitis (PBC) (16). Indeed, reduced FoxP3 expression in Treg has been described in the portal tracts of patients with PBC (17). Our group has previously reported the existence of a gut-liver link with the aberrant homing of mucosal $\mathrm{T}$ cells from the gut to the liver and extra-intestinal manifestations being seen in inflammatory bowel disease (18-20). Biliary epithelial inflammation has also been associated with the accumulation of CCR10-expressing Treg around the bile ducts in the liver (21).

In the setting of acute liver injury, such as acute viral hepatitis A, the size of the Treg pool was contracted due to Treg apoptosis via a Fas-mediated mechanism (22). Hepatitis B (HBV) pathogenesis is immunologically mediated and increased frequencies of $\mathrm{CD}^{+}{ }^{+} \mathrm{CD} 25^{\text {high }} \mathrm{CD} 45 \mathrm{RO}^{+}$Treg and cytotoxic T-lymphocyte-associated antigen 4 (CTLA-4) cells were noted in the peripheral blood of patients compared with controls and in patients who had recovered from a previous episode of $\mathrm{HBV}$ infection $(23,24)$. However, in HBV-related acute or chronic liver failure, while there was a reduction noted in $\mathrm{CD}^{+} \mathrm{T}$ cells, Treg numbers remained unchanged (25). In addition, serial biopsies from patients chronically infected with hepatitis $\mathrm{C}$ virus, taken during and after antiviral therapy, suggested that intrahepatic $\mathrm{CD}^{+} \mathrm{CD} 25^{\text {high }} \mathrm{FOXP} 3^{+}$Treg frequencies were increased upon interferon and ribavirin therapy in about half of patients, indicating stronger regulation of intrahepatic immunity by Treg during antiviral therapy (26). It is generally accepted that Treg are not beneficial in the setting of liver cancer as an increased Treg frequency correlates with $\mathrm{CD} 8^{+} \mathrm{T}$ cell impairment and poor survival of patients (27). All this body of evidence suggests that Treg play a major role in different types of liver diseases.

The Treg population has been classified as $\mathrm{CD} 25^{+} \mathrm{CD} 45 \mathrm{RA}^{+}$ FOXP3 $3^{\text {low }}$ resting, CD $25^{++} \mathrm{CD} 45 \mathrm{RA}^{\text {neg }} \mathrm{FOXP} 3^{\text {high }}$ activated, suppressive Treg and $\mathrm{CD} 25^{+} \mathrm{CD} 45 \mathrm{RA}^{\text {neg }} \mathrm{FOXP} 3^{\text {low }}$ cytokine-secreting non-suppressive Treg (28) (Figure 1). We recently described intrahepatic Treg as predominantly effector memory lymphocytes with PD $1^{\text {low }}$, CD69 $9^{\text {high }}$ phenotype (15) and expressing both hepatic homing CXCR3 and biliary tropic CCR6 chemokine receptors (14) (Figure 1).

\section{SUPPRESSIVE MECHANISMS OF REGULATORY T CELLS}

Regulatory $\mathrm{T}$ cells are potent mediators of self-tolerance in the periphery and function via multiple mechanisms to achieve immune modulation. Treg exert their functions by (i) inhibiting the function or maturation of antigen-presenting cells (APCs), (ii) destroying target cells by inducing apoptosis, (iii) causing metabolic disruption via the adenosine pathway, and (iv) by secreting immunosuppressive cytokines, transforming growth factor beta (TGF- $\beta$ ), and IL-10 or competitive consumption of survival cytokines in particular IL-2 (Figure 2).

T-lymphocyte-associated antigen 4 (CTLA-4) protein expression on Treg plays an important role in the suppressor function of Treg (29). In particular, deficiency of CTLA-4 in Treg impairs their suppressive function to result in fatal T cell-mediated autoimmune disease. CTLA-4 via the process of trans-endocytosis depletes its two ligands, CD80 and CD86 from dendritic cells (DCs), thereby removing their availability to act as costimulatory ligands through CD28 (30) (Figure 2). In vitro studies have also identified that CTLA-4 can additionally suppress T-cell proliferation via upregulation of several essential amino acid consuming enzymes, including indolamine 2,3-dioxygenase, histidine ammonia lyase, nitric oxide synthase 2 , and L-threonine 3-dehydrogenase in APC through binding CD80 on the APC cell surface (31). IDO-positive DCs represent a regulatory subset of APCs in humans (32) (Figure 2). Regulation of tryptophan metabolism by indolamine 2,3-dioxygenase (IDO) in DCs is a highly versatile modulator of immunity. IDO converts tryptophan to kynurenine, which inhibits the proliferation of effector T cells (33) (Figure 2) but promotes FoxP3 induction in a mechanism involving reduced PI3K/mTOR signaling (31). Importantly, we have shown that human intrahepatic Treg reside close to DCs and effector $\mathrm{T}$ cells to exert their suppressive function in the areas of chronic hepatitis, either in the lobules or in the areas of interface hepatitis (34).

TGF- $\beta 1$, an immunosuppressive cytokine, supports the maintenance of FoxP3 expression, regulatory function, and homeostasis in peripheral Treg (35). It is also a crucial cytokine, which dictates the development of a Treg versus Th17 lineage (36) and limits T effector proliferation via induction of essential amino acid catabolizing enzymes in APCs. IL-10 released by Treg also promotes essential amino acid depletion via upregulation of certain catabolizing enzymes in APCs (31). The liver is enriched with TGF- $\beta 1(37,38)$ (Figure 3). Recently, CD103+ intestinal DCs have been shown to promote a tolerogenic environment via integrin $\alpha v \beta 8$-mediated activation of TGF- $\beta$ (39), and DCs lacking $\alpha v \beta 8$ fail to induce Treg (40).

Treg could also suppress or kill responder $\mathrm{T}$ cells after cell to cell contact in a perforin-dependent and independent manner by granzymes A and B $(41,42)$. Treg can also inhibit $\mathrm{T}$ cell 


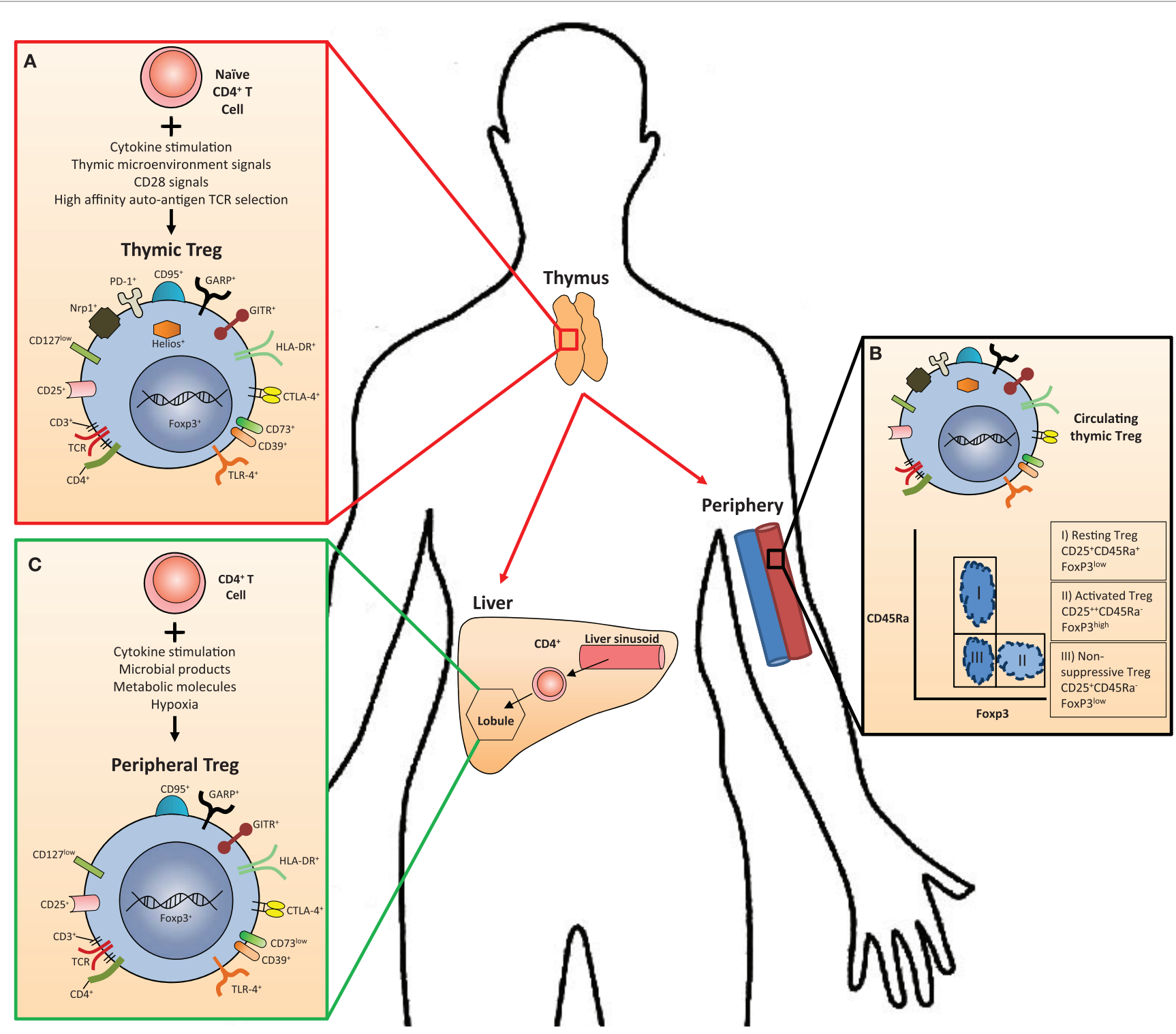

FIGURE 1 | The anatomical location of Treg cell subsets and their phenotypic markers in humans. (A) Thymus-derived Treg (tTreg) cells are generated in the thymus from naive $\mathrm{CD} 4^{+} \mathrm{T}$ cells in combination with several stimulating factors. They express transcription factors and surface markers specific to all Treg subsets in addition to those specifically upregulated only in tTreg, such as PD-1, Helios, and Nrp-1. (B) Peripheral blood flow contains all circulating Treg subsets, including three subpopulations that may be defined by their expression of CD45Ra and FoxP3. (C) In tissues such as the liver, naive CD4 ${ }^{+}$cells may differentiate into peripherally derived Treg cells (pTreg) in response to stimulating factors. These cells express many of the same transcription factors and surface markers as tTreg with notable differences, such as reduced Helios, Nrp1, CD73, and PD-1 expression.

proliferation by inducing pericellular adenosine from extracellular nucleotides $(43,44)$, which is catalyzed by ectoenzymes, CD39, and CD73 expressed on Treg $(45,46)$. The coordinated expression of $\mathrm{CD} 39 / \mathrm{CD} 73$ on Treg and the adenosine A2A receptor on activated $\mathrm{T}$ effector cells generates immunosuppressive loops, implementing the inhibitory function of Treg cells $(43,47)$ (Figure 2). We reported previously that there is an increase in the frequency of intrahepatic Treg in inflamed human livers (34) in parallel with total CD4 T cells, and they had high expression of their functional markers such as CTLA-4, CD39, and also secreted IL- 10.
IL-2 is a potent inducer of T-cell proliferation and T-helper cell differentiation and is necessary for the survival and function of memory $\mathrm{T}$ cells. It is also important for the development, survival, and function of Treg $(45,48,49)$. Treg have higher expression of the high-affinity IL-2 receptor subunit, CD25, than effector T cells; thus, Treg can suppress effector cell proliferation and differentiation by competitive consumption of IL- 2 when located in close proximity (50). However, the functional capacity of intrahepatic Treg is reduced in the IL-2-deficient inflamed hepatic microenvironment (15). We demonstrated that the main source of intrahepatic IL-2 is activated T effector cells, and this cytokine 


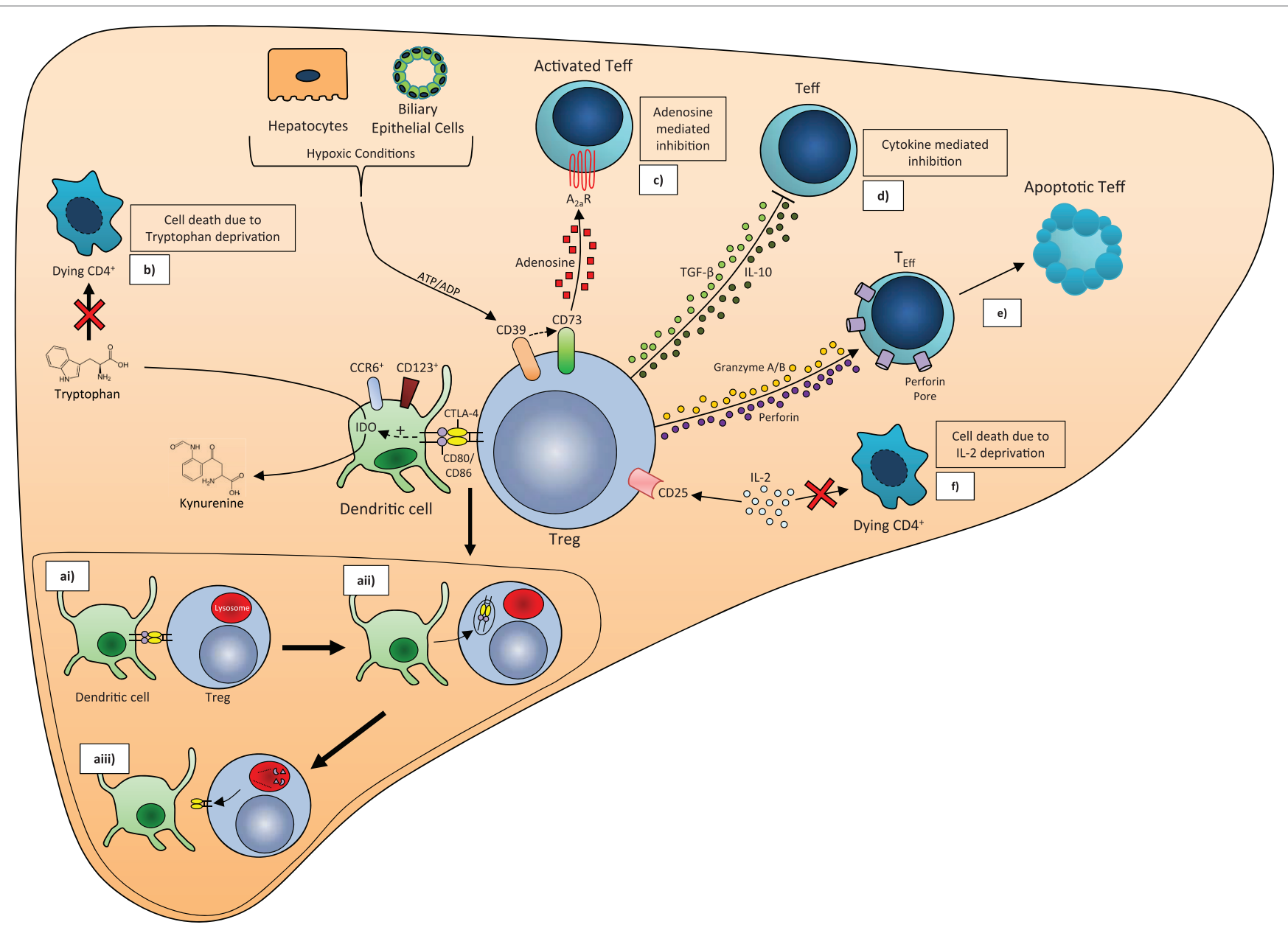

FIGURE 2 | Treg mechanisms of action. (a) CTLA-4/CD80/CD86 trans-endocytosis. (ai) CTLA-4 on the surface of Treg binds to CD80/CD86 on the dendritic cell surface. (aii) CTLA-4 and CD80/CD86 are brought into the Treg via endocytosis. (aiii) CD80/CD86 fuses with lysosomes to be broken down, while CTLA-4 is recycled to the cell membrane. (b) IDO-mediated tryptophan deprivation. Binding of CTLA-4 and CD80/CD86 stimulates induction of the enzyme Indoleamine 2 , 3-dioxygenase (IDO) in $\mathrm{CD}^{2} 23^{+} \mathrm{CCR}^{+}$dendritic cells, which catalyzes the conversion of Tryptophan to $\mathrm{N}^{\prime}$-Formylkynurenine. The resulting Tryptophan depletion leads to CD4 $^{+}$cell death. (c) Conversion of ATP to adenosine via CD39/CD73. CD39 and CD73 expressed on the Treg cell surface convert ATP/ADP released from respiring hypoxic cells into adenosine, which binds to receptors on activated T effector (Teff) with an inhibitory effect. Depletion of ATP also suppresses Teff proliferation. (d) Cytokine release. TGF- $\beta$ and IL-10 released by Treg inhibit Teff cell proliferation and activation. (e) Induction of apoptosis. Release of Granzyme A, Granzyme B, and perforin by Treg leads to apoptosis of Teff. (f) IL-2 deprivation. Deprivation of IL-2 from CD4+ T cells by CD25 on the Treg surface leads to cell death.

is crucial for Stat5 signaling in Treg (15). IL-2 is also required for the homeostatic maintenance of Treg. Taken together, such low intrahepatic IL-2, which appears reduced further in disease, might contribute to a lack of Treg-conferred protection and the progression of immune-mediated liver diseases. Indeed, autoimmune diseases can be induced by IL-2 neutralization or defective IL-2 production $(51,52)$.

Thus, Treg exert suppression in multiple pathways. The mechanism is dependent on the specific tissue and its microenvironment (Figure 2).

\section{HEPATIC MICROENVIRONMENT AND REGULATORY T CELLS}

Intrahepatic Treg are residing in a microenvironment, which is deprived of oxygen and enriched with microbes, metabolic products; inflammatory cytokines, and hormones, which all play a role in Treg differentiation and function (Figure 3). The liver is enriched with fat-soluble vitamins. All-Trans retinoic acid (ATRA), a metabolite of vitamin A, is enriched in Ito cells (stellate cells) and plays a pivotal role in maintaining the stability and function of Treg in the inflammatory milieu $(53,54)$. Retinoic acid can also directly promote TGF- $\beta$-mediated conversion of naive $\mathrm{T}$ cells to cells of FoxP3 ${ }^{+}$Treg phenotype $(55,56)$. In addition, retinoic acid can prime human DCs to induce gut homing, IL-10-producing Treg (57) (Figure 3).

The active form of vitamin D, 1,25-dihydroxyvitamin D3 and IL-2 synergistically combine to inhibit $\mathrm{T}$ cell production of inflammatory cytokines and promote development of Treg expressing CTLA-4 and FoxP3 (58) (Figure 3). One recent report showed that short-chain fatty acids (SCFA) from gut microbiota-derived bacterial fermentation products regulate the 


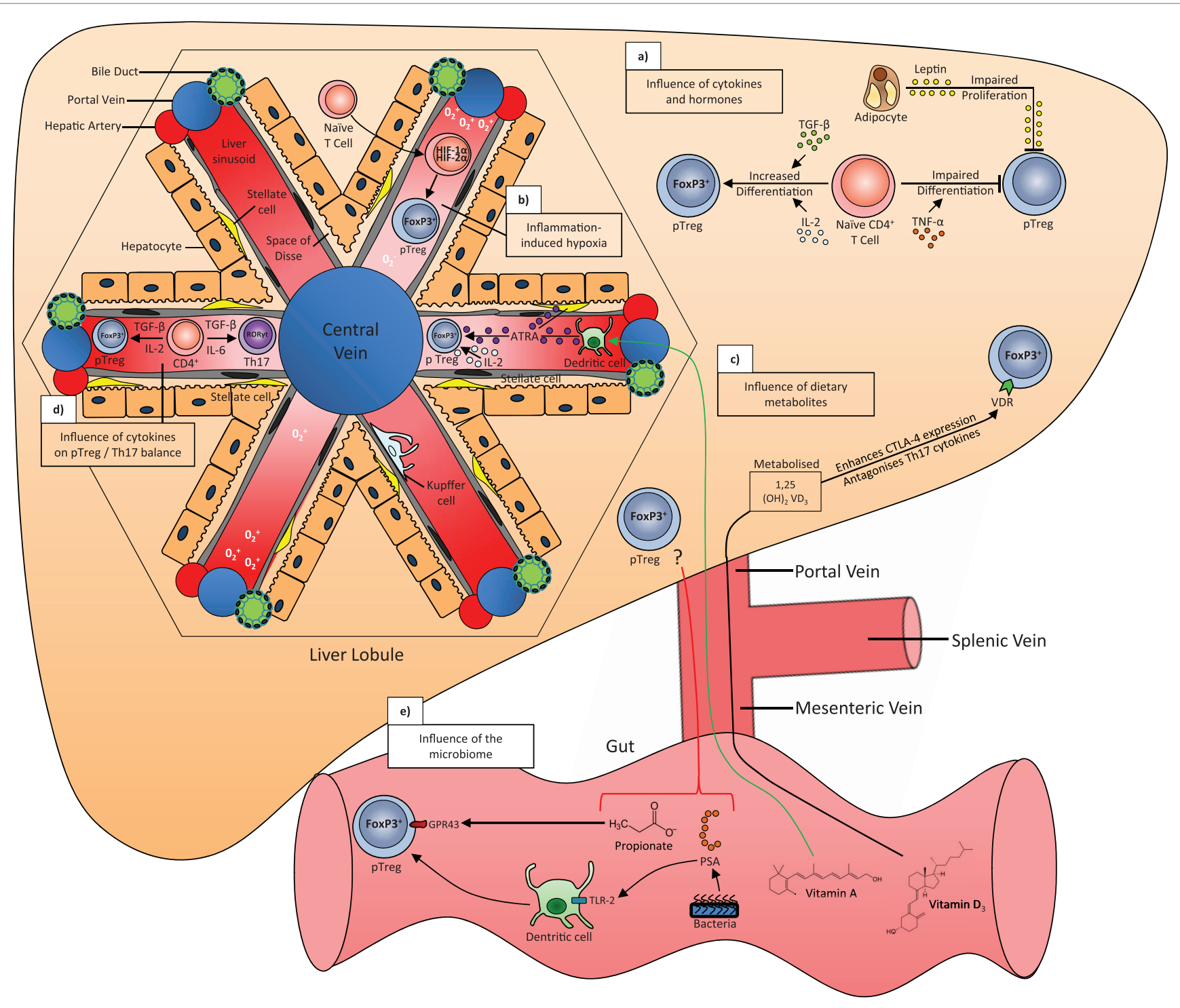

FIGURE 3 | The influence of cytokines, hypoxia, dietary metabolites, microbiota, and hormones on the generation of peripherally derived regulatory T cells ( $\mathbf{p T r e g}$ ) in the liver. (a) TGF- $\beta$ and IL-2 signal to promote the differentiation of naive CD4+ $T$ cells, while TNF- $\alpha$ impairs differentiation. Leptin released by adipocytes impairs the proliferation of pTreg cells. (b) Cytokines released during liver inflammation can lead to hypoxic conditions, which stabilizes the transcription factors hypoxia-inducible factor $1 \alpha$ and $2 \alpha(\mathrm{HIF}-1 \alpha / \mathrm{HIF}-2 \alpha)$ in naive CD4 ${ }^{+}$T cells. These factors stimulate FoxP3 expression and a move toward a pTreg phenotype. (c) Dietary vitamin D3 brought to the liver via the portal vein is metabolized into its active form 1,25 $\left(\mathrm{OH}_{2}\right)$ VD3 or calcitriol, which enhances CTLA-4 expression and antagonizes Th17 cytokines in all T cells, including pTreg, via the vitamin D receptor (VDR). Dietary vitamin A is converted to all-trans retinoic acid (ATRA) by CD103+ dendritic cells in the liver sinusoid, which in combination with ATRA released by stellate cells and IL-2, stabilizes FoxP3 and the pTreg phenotype. (d) TGF- $\beta$ in combination with IL-2 or IL-6 will differentiate naive CD4+ T cells into pTreg or Th17 cells, respectively. (e) Propionate is a short-chain fatty acid that is metabolized by gut microbes and binds to GPR43 receptor to stabilize the pTreg phenotype. The bacteria component polysaccharide A (PSA) binds to TLR-2 on dendritic cells, which increases pTreg differentiation. The influence of these products in the liver is unknown.

size and function of the colonic Treg pool and protect against colitis, suggesting that abundant microbial metabolites underlie adaptive immune microbiota coadaptation and promote colonic homeostasis (59). We have also reported that the inflamed liver microenvironment is enriched with pro-inflammatory cytokines IL-1, IL-12, IL-6, IL-8, and TNF $\alpha$, but deprived of the Treg survival cytokine IL-2 (15). Nonetheless, although they present a somewhat reduced regulatory capacity, intrahepatic Treg still possess an intact functional capacity and maintain their lineage for a short time in culture conditions that mimic the intrahepatic environment (15).

There is a shift in metabolic supply-and-demand ratios during inflammation. Tissue hypoxia within inflammatory lesions dictates an anti-inflammatory program by driving expression of hypoxia-inducible factor (HIF)- $1 \alpha$ that acts to increase the frequency and suppressive properties of thymic Treg $(60,61)$. 
Indeed, hypoxic Treg were more effective than normoxic cells in suppressing the proliferation of effector lymphocytes (61). The hepatic microenvironment is a hypoxic atmosphere especially around zone 3, where cells are closer to the central vein and most distant from the hepatic artery oxygen supply. Thus, while not proven, a gradient in Treg potency might be expected through the liver.

The liver is continuously exposed to gut microbes and bacterial toxins via its portal venous flow. It is clear that the microbiome has a strong influence on the immune system. For example, breast-fed infants develop robust populations of memory $\mathrm{T}$ cells as well as T helper 17 (Th17) cells within the memory pool, whereas bottlefed infants do not, and this may partly explain the variation in human susceptibility to conditions with an immune basis, as well as the variable protection against certain infectious diseases (62). Oral bacteria administration in mice also promotes Treg and alleviates bowel inflammation in a model of immune-mediated colitis (63); thus, the microbiome may serve as a target for future Treg-based immunotherapies.

\section{RECRUITMENT AND POSITIONING OF Treg TO THE INFLAMED LIVER}

Leukocyte trafficking and positioning within tissues is directed by chemokines. Thus, chemokines play critical roles in regulating immune responses and inflammation $(64,65)$. Chemokines can be classified into "inflammatory" and "homeostatic/constitutive" based on whether they are induced by inflammation or constitutively expressed and involved in homeostatic immune regulation (64). Hepatic Treg express a unique range of chemokine receptors, which interact with corresponding chemokines, and these receptors are crucial for their homing and positioning in the inflammatory liver tissues. Human intrahepatic Treg express the chemokine receptor CXCR3 for recruitment across hepatic sinusoids, CCR4 for positioning close to hepatic DCs and both CXCR3 and CCR6 chemokine receptors for positioning around bile ducts $(15,34)$. This chemokine receptor expression profile is essential for Treg to locate at the site of inflammation and to interact with other immune cells. CXCR3 deficiency has been shown to exacerbate liver disease and abrogates tolerance in mouse models of immune-mediated hepatitis (66).

\section{CLINICAL APPLICATION OF Treg}

As has been discussed, Treg play a pivotal role in controlling the magnitude of immune responses to provide tolerance to selfantigens and to limit tissue damage caused by immune activation in response to innocuous antigens. Given the contribution of aberrant immune control in the progression of disease including: (1) suppressed effector immune response which results in unwanted Treg activity in cancer, (2) impaired immuneregulatory function in autoimmune or inflammatory diseases, and (3) the deleterious consequences of life-long immunosuppression therapy following organ transplantation, the prospect to control disease progression through targeting the regulatory cells in settings of cancer, solid organ and hematopoietic cell transplantation, transplant rejection, and autoimmune diseases has been an attractive option for clinicians over many years.

The cytokine IL-2 is essential for the function and expansion of Treg (49). Thus, to improve immune regulation through lowdose, IL-2 therapy, which targets the Treg selectively in contrast to effector, has been tested with positive outcomes in human autoimmune-related diseases in Phase I and II settings (67-70).

The establishment over recent years of good manufacturing practice (GMP)-compliant reagents and equipment that can allow the isolation of cells according to their expression profile of certain surface proteins has made it possible to isolate Treg from the peripheral circulation as a cell immunotherapy. The concept underlying this "Regulatory T cell therapy" is that administering a concentrated source of a desired population of Treg can tip the balance of the patient's immune system to enhance its regulatory capacity. It builds on the knowledge that a lack of Treg function due to mutation of the Treg lineage-defining transcription factor FOXP3 leads to the X-linked autoimmune syndrome immune dysregulation, polyendocrinopathy, enteropathy X-linked syndrome (IPEX) (71), and, upon the seminal observation by Sakaguchi and colleagues, that giving $\mathrm{CD} 4{ }^{+} \mathrm{CD} 25^{+}$Treg could prevent autoimmune disease (2). In this section, we discuss developments in the field of Treg immunotherapy and its potential to be used to treat liver diseases in the future.

\section{GENERATION OF GMP-COMPLIANT CLINICAL GRADE Treg FOR CELL THERAPY}

To be used therapeutically, a cellular product must be deemed GMP-compliant. This has massive implications upon its production compared with a basic laboratory reagent as the final product and all the reagents and equipment used in its manufacture must exceed a standard clinical quality (purity) and sterility. Accordingly, all staff involved in its preparation must be highly skilled in aseptic procedures and must receive regular re-training. There must be a detailed $\log$ of the production and characterization of the final product. Altogether, this imposes extremely high overheads to the production of cellular therapies and with regard to Treg cell therapy has further limited the precise phenotypic character that can be achieved both for practical and for financial reasons. Consequently, the Treg used in trials until now have differed.

To date, we can define three categories of GMP-grade clinical Treg: first generation $\left(\mathrm{CD} 4^{+} \mathrm{CD} 25^{+}\right)$; second generation, bone fide Treg $\left(\mathrm{CD} 4^{+} \mathrm{CD} 25^{+} \mathrm{CD} 127^{\text {low/- }}\right)$, and third generation naive Treg $\left(\mathrm{CD} 4^{+} \mathrm{CD} 25^{+} \mathrm{CD} 127^{\text {low } /-} \mathrm{CD} 45 \mathrm{Ra}^{+}\right)$(Figure 4). There are two options to achieve GMP clinical grade Treg, bead-based GMP technology and flow sorting technology. While first generation Treg can be isolated by magnetic bead-based approaches alone, such as CD8 and CD19 depletion followed by CD25 enrichment, there are no GMP bead reagents to deplete CD127expressing effectors. Isolation of second and third generation Treg that are exclusively CD127 low/- depends on the availability of a GMP-compatible flow sorting facility. Tyto technology (Miltenyi Biotec) now exists that can facilitate the isolation and expansion of a highly pure second $\left(\mathrm{CD} 4^{+} \mathrm{CD} 25^{+} \mathrm{CD} 127^{\text {low/- }}\right)$ and 


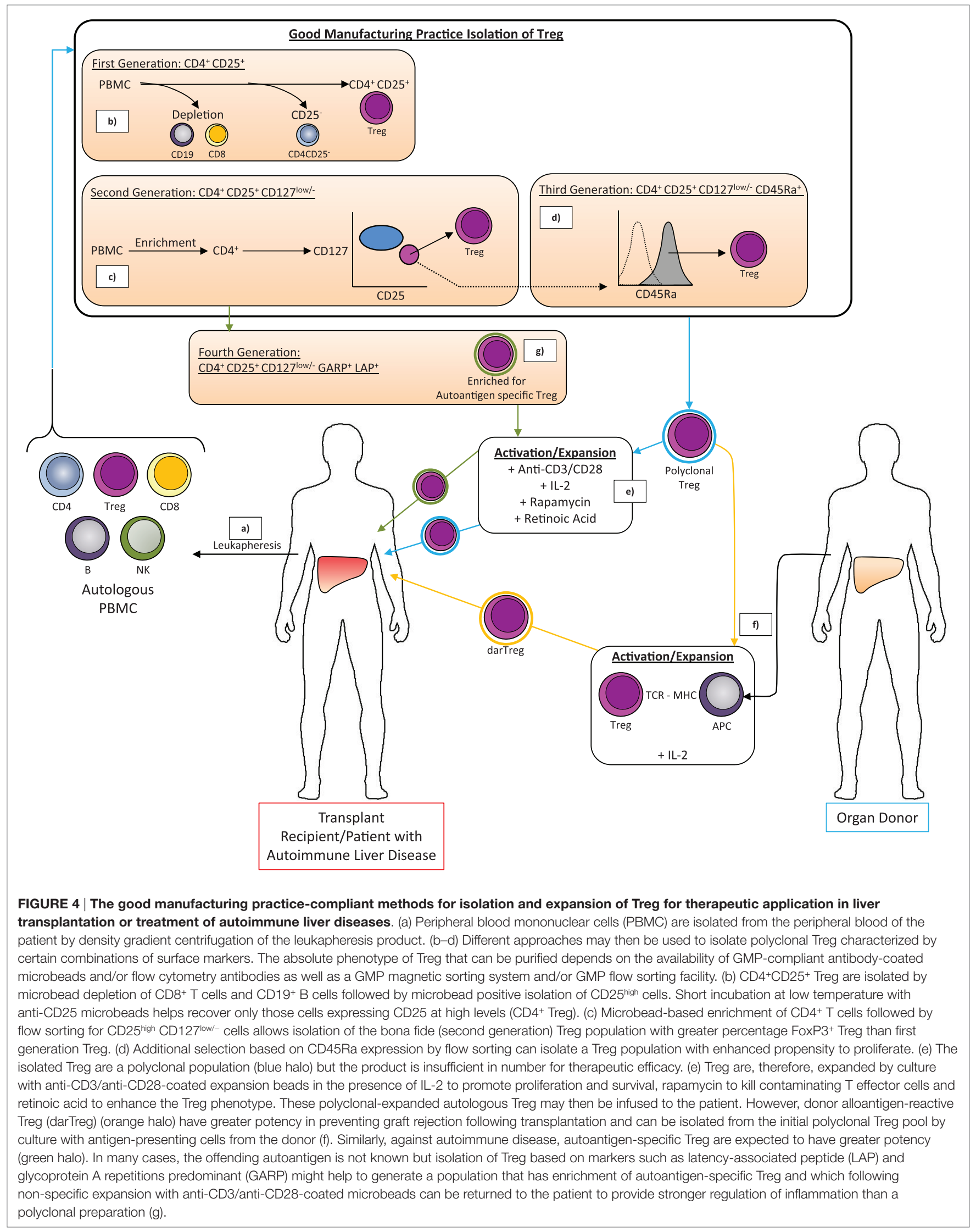


third generation $\left(\mathrm{CD} 4^{+} \mathrm{CD} 25^{+} \mathrm{CD} 127^{\text {low }-} \mathrm{CD} 45 \mathrm{Ra}^{+}\right)$GMP Treg preparation straight from a leukapheresis product within a closed system, reducing the risk of loss of sterility and optimizing the purity of the preparation from the start. Moreover, by including Rapamycin and Retinoic acid in the culture cocktail during subsequent expansion, it is possible to ensure that loss of purity through the outgrowth of any contaminating effector $\mathrm{T}$ cells is not of concern. Rapamycin precludes the expansion of effector but not regulatory $\mathrm{T}$ cells via differential downstream signaling from the IL-2R (72). Furthermore, additional supplementation with IL-2 \pm retinoic acid can help to support Treg proliferation and potentiate the functional phenotype (73), and it is possible to measure the demethylation status of the Treg-specific demethylated region (TSDR) prior to administration of the cell therapy product to the patient to verify purity. Although percentage demethylation boundaries are not yet rigorously defined, such could be implemented during trials to help restrict any adverse events based on known lack of purity.

\section{Treg IMMUNOTHERAPY FOR LIVER TRANSPLANTATION AND AUTOIMMUNE LIVER DISEASES}

To date, GMP Treg therapy has not been reported in the treatment of the liver diseases either in preventing rejection of donor organs, preventing GVHD posttransplant, enabling withdrawal of immunosuppressants or overcoming any need for them posttransplant, or in inducing or maintaining states of remission in the pre-transplant setting, but evidence from animal studies $(2,3$, 74,75 ) and trials of Treg immunotherapy in other human disease backgrounds provide sound rationale for the attempted use of this therapy in liver medicine in the future. This is particularly important in an era when the demand for liver transplants exceeds the availability of matched donor livers. Currently, the first clinical trials are underway, investigating the safety and feasibility of Treg therapy in renal transplantation $(76,77)$, and it is likely that outcomes of this trial could be applicable to similar solid organs such as the liver.

\section{Application of Treg Immunotherapy to Induce Liver Transplantation Tolerance}

Successful solid organ transplantation requires the regulation of two immune reactions: (i) antigenic activation of the donor immune system against the host that if not restrained leads to GVHD and (ii) antigenic activation of the host immune system toward the graft, which can lead to graft rejection. GVHD is a major complication in the setting of bone marrow transplantation, owing to the preponderance of $\mathrm{T}$ cells in bone marrow, but in solid organ transplant it is generally of lesser concern. Moreover, the tolerogenic nature of the liver and its ability to regenerate (78) means that the recipient-donor match in liver transplant need be less stringent and the recipient to donor immune response is perhaps the area of gravest concern therapeutically. This is currently targeted through life-long immunosuppression, but leaves individuals at risk of opportunistic infections, diabetes, hypertension, and malignancy (79).
The first human studies of Treg cell therapy explored its potential in the regulation of GVHD and tested HLA-matched sibling donor-derived expanded $\mathrm{CD} 4^{+} \mathrm{CD} 25^{+} \mathrm{CD} 127^{\text {low/ }}$ (second generation) Treg to combat the difficulty in treating GVHD, following allogeneic bone marrow or stem cell transplantation $(80,81)$. Although, these initial studies had mixed outcomes, they provided hope for Treg therapy in GVHD and highlighted the possible importance of timing and dose. A more recent Phase I dose escalation study of Treg tested the use of partially HLAmatched donor umbilical cord blood as opposed to peripheral blood (82).

Excitingly, Todo and colleagues brought a new concept of Treg-based therapy to the table of operational tolerance in living donor liver transplantation (83). In this instance, the straightforward coculture of irradiated donor lymphocytes collected from a leukapheresis product with recipient lymphocytes in the presence of anti CD80/86 monoclonal antibodies generated a recipient cell product that proved enriched with cells of regulatory phenotype. In vitro, these cells inhibited the proliferation of recipient cells in response to donor cell stimulation in a dose-dependent manner, and, in vivo, the therapy allowed immunosuppressive agents to be tapered and completely discontinued within 18 months. This is revolutionary in the field as at the time of reporting $7 / 10$ subjects had had successful weaning and remained drug free for up to 33 months. Successful weaning from immunosuppressant has previously been described between 3 and 11 years following transplant with longer delay giving higher (up to $80 \%$ ) success (84). Only three individuals who were patients with autoimmune liver disease did not tolerate the novel therapy well, and, thus, its potential in the setting of autoimmune liver disease transplantation tolerance requires further consideration (83).

\section{Application of Treg Cell Therapy to Restore Peripheral Immune Tolerance in Autoimmune Liver Diseases}

Regulatory $\mathrm{T}$ cell therapy has not yet been tested in the AILD in humans. Since there have been no advances in new therapies for these diseases in the last three decades, observations of reduction of Treg and/or impairment of Treg function in these diseases supports the concept of Treg therapy in $\operatorname{AILD}(12,15,17$, 85). Treg therapy is an attractive option and especially now that standard operating procedures (SOPs) and GMP reagents and equipment are in place for the automated and safe manufacture of patient-specific cell-based therapies. It is also being considered as a future therapy for a number of other autoimmune diseases, including inflammatory bowel disease and Crohn's disease (86, 87), rheumatoid arthritis (88), and systemic lupus erythematosus (SLE) (89). Although a lack of regulatory control is clear in these diseases, the precise roles of Treg in the pathogenesis of these diseases are unclear as studies have been contradictory with regard to changes in frequency and impaired functionality, and it may be that the lack of control is due to defects in the capacity of the antigen-presenting and/or effector cells to be downregulated by the regulatory cells.

To date, the seminal pioneering studies in this arena have been in type- 1 diabetes, an autoimmune disease of the pancreatic beta 
islet cells wherein destruction of the beta islets by autoreactive $\mathrm{T}$ cells leads to loss of production of the hormone insulin, which is vital to the regulation of blood glucose. The first safety study in humans was in 2012 in a pediatric cohort. Ten children were given 1 or $2 \times 10^{7} \mathrm{CD} 4^{+} \mathrm{CD} 25^{+} \mathrm{CD} 127^{\text {low } /-} \mathrm{Treg} / \mathrm{kg}$ body weight without any adverse events. Significant increases in the proportions of peripheral Treg were measured after transfer and importantly at 6 months post treatment. Eight out of the 10 children, receiving Treg therapy, were in remission with 2 weaned off from insulin therapy completely. This was in comparison to the control cohort, all of whom continued to require insulin therapy (90).

Subsequent work by Tang and colleagues has evaluated safety in adults, testing escalating doses of $\mathrm{CD} 4^{+} \mathrm{CD} 25^{+} \mathrm{CD} 127^{\text {low }-}$ Treg between $5 \times 10^{6}$ and $3.2 \times 10^{8}$ cells. No serious adverse events were observed with the dose escalation study, and an improvement in C-peptide level was noted (91). By including $\left[6,6-{ }^{2} \mathrm{H}_{2}\right]$ glucose, which incorporates into the deoxyribose moiety of newly synthesized DNA during expansion, the researchers were able to non-radioactively label the Treg and follow their persistence in the patient following infusion. Excitingly, although only $25 \%$ of the peak label was retained on cells at 90 days, it could still be detected up to 1 year, suggesting maintenance of the infused Treg (91). Furthermore, expressions of Treg-defining markers, including FoxP3, CD25, and CD127, remained stable in Treg post infusion, and there was not a shift toward a T effector cytokine profile. Thus, these studies in type- 1 autoimmune diabetes provide good support for attempting Treg immunotherapy to treat AILDs, including autoimmune hepatitis (AIH), primary sclerosing cholangitis (PSC), and PBC in the future. However, no study has yet verified that Treg cells administered actually reach the site of disease, establish persistence at the site and maintain a stable phenotype overtime. The recent study by Todo and colleagues applying Treg in the setting of living donor liver transplant did perform liver biopsies at regular intervals during follow up to detect the graft inflammation and fibrosis, but no immunology study was done on the liver allograft after Treg infusion to investigate the localization and fate of the infused cells at the tissue level (83). To fully understand outcomes of therapeutic efficacy in future trials of the therapy, it would be of advantage if these questions could be tackled through biopsy and or/novel in vivo imaging methods post treatment.

\section{OPTIMIZATION OF REGULATORY T CELL THERAPY FOR APPLICATION IN THE LIVER DISEASES}

Taken together, studies using GMP Treg, whether first or second generation, appear promising although clearly the optimization of factors including dose, timing relative to transplant/disease stage, as well as the choice of immunosuppression regimen and the frequency of Treg reapplication are important, and it is likely that each of these will be dictated by the individual situation (prophylactic pre or posttransplant versus autoimmunity/GVHD/ rejection), the grade of the individual's disease, and whether the patient's disease is in remission (requiring withdrawal of standard medication) or in relapse (requiring settling of active immune reactions as well as withdrawal of standard medications). Given that Cyclosporine reduces Treg number, immunosuppression therapies used together with Treg therapy should be tailored to a rapamycin-based regimen along with Tacrolimus, which increases Treg survival. Patients with active viral infection and previous history of malignancy should be excluded from any Treg clinical trial as Treg would have a negative impact on the disease process.

It seems likely that isolated cells will have to be expanded in order to be of adequate number to be used in therapy. Hence, one caveat will, therefore, be the reliable expansion of autologous Treg cells for all patients since most studies, to date, have reported a few subjects who were enrolled but failed to receive treatment or treatment at the intended dose due to an inadequate cell yield.

The question over the preparation of the Treg also remains. Until now the Treg tested in clinical trials have been polyclonal and, thus, have ability to function through indirect pathways but also specifically due to a number within the mix that have donor antigen specificity (namely alloantigen-specific Treg). With a view to optimize Treg for transplantation therapy, polyclonal and alloantigen-specific Treg have been compared. Alloantigenspecific Treg represent those Treg that are activated by donorspecific antigens and can be expanded from polyclonal Treg populations in mixed lymphocyte reactions with donor APCs. By contrast polyclonal Treg are expanded with anti-CD3/antiCD28-coated expander beads. Alloantigen-specific $\mathrm{T}$ cells can be identified and selected for further expansion based on their induction of activation markers such as CD69 and CD71. The fact that the therapeutic product created by Todo et al. through mixed lymphocyte reaction had greater suppressive ability over recipient $\mathrm{T}$ cells activated by donor as opposed to third-party stimulation was clear evidence of underlying allospecific regulatory activity having been raised within the expanded culture, and, as such, using a system to generate greater donor specificity might be advantageous and should allow considerably reduced numbers of Treg to be used (83). The value of alloantigen-specific Treg in transplantation tolerance was cleverly demonstrated in vivo using a humanized mouse model of human skin graft immune rejection. Allogeneic Treg expanded on myeloid DCs from the skin were more effective at limiting dermal and inflammatory phenotypes of skin rejection by infusions of allogeneic $\mathrm{T}$ effector cells than polyclonal Treg (74). Various methods have been proposed to generate GMP-compliant donor alloantigen reactive Treg (darTreg) for therapeutic application. Appropriate alternative cell types to incorporate in coculture with recipient $\mathrm{CD} 4^{+} \mathrm{CD} 25^{+}$ Treg to drive the expansion of darTreg include donor PBMCs, donor monocyte derived DCs, and donor B cells (92) activated on 3T3 fibroblasts expressing CD40L (93). A number of current phase 1 and phase 2 clinical trials propose the application of darTreg as opposed to polyclonal Treg (Table 1). Similarly, in autoimmunity, where models of disease propose the likely hood of only a defined autoantigen, antigen-specific Treg may be the way forward, but this requires knowledge of the offending antigen. In the liver diseases, autoantigens for type II AIH (94) and PBC (95) are known but for type I AIH and PSC are yet to be discovered precluding the benefits of antigen-specific therapy at the present time. Nonetheless isolation of Treg expressing 
markers of activation such as latency-associated peptide (LAP) and glycoprotein A repetitions predominant (GARP) might help to generate a product with a higher proportion of antigen-specific Treg (Figure 4).

Clinical trials of Treg therapy for solid organ transplantation and autoimmune diseases that are listed on www.ClinicalTrials. gov and currently recruiting are summarized in Table $\mathbf{1 .}$

\section{SUMMARY}

Overall, Treg hold promise as personalized therapy in the treatment of liver diseases and, in the future, may be applied in the non-transplant as well as post-transplant setting to overcome or minimize the use of broad spectrum immunosuppressant medications that have unfavorable side effects (79). Their mechanisms of function vary at different tissues. While Treg therapy has been applied in other autoimmune disease settings, such as diabetes and SLE, successful application in the treatment of the liver diseases, including autoimmune-related liver patients, may require consideration of the impact of the inflamed liver microenvironment itself which is enriched with cytokines, microbes, and metabolites. Dissecting the clonotype and gene signature would facilitate exploration of antigen specificity, and therapy can be optimized by administering antigen-specific Treg. Notably, it is already clear that the effective proliferation and function of Treg is dependent on IL-2, yet the liver microenvironment is deficient in IL-2 (15). Thus, it is anticipated that Treg therapy for liver diseases would

TABLE 1 | Clinical trials in regulatory T cell therapy in solid organ transplantation or autoimmune diseases that were listed as recruiting in the www. ClinicalTrials.gov registry at the time of manuscript preparation (accessed 04-05-2016).

\begin{tabular}{llll}
\hline $\begin{array}{l}\text { Title of study/www. } \\
\text { ClinicalTrials.gov identifier }\end{array}$ & Sponsor & Location of study & $\begin{array}{l}\text { Start date/end date/ } \\
\text { enrollment/phase }\end{array}$ \\
\hline $\begin{array}{l}\text { deLTa: darTregs in liver } \\
\text { transplantation/NCT02188719 }\end{array}$ & NIAID & $\begin{array}{lll}\text { 1. University of California } \\
\text { San Francisco, USA }\end{array}$ & $\begin{array}{l}\text { December 2014/ } \\
\text { January 2022/24/ } \\
\text { phase 1 }\end{array}$ \\
& & $\begin{array}{l}\text { 2. Mayo Clinic } \\
\text { Minnesota, USA }\end{array}$ &
\end{tabular}

The ONE study: Infusion of Treg in kidney transplant recipients/ NCT02091232; The ONE study is a unified approach to evaluating cellular immunotherapy in solid organ transplantation

ONETreg1: The ONE study UK Treg Trial/NCT02129881.

DART: darTreg therapy in renal transplantation. The ONE study US Treg Trial/NCT02244801

ARTEMIS: darTregs for calcineurin inhibitor reduction/NCT02474199

ThRIL: Safety and efficacy study of Treg therapy in liver transplant patients/NCT02166177

TASK: Treg adoptive therapy for subclinical inflammation in kidney transplantation/NCT02088931

TASK: Treg therapy in subclinical inflammation in kidney

transplantation NCT02711826

Autologous polyclonal Treg for Lupus/NCT02428309

$\begin{array}{lll}\text { Massachusetts } & \text { Collaboration of US } & \text { May 2014/May } \\ \text { General Hospital } & \text { and EU Centers } & \text { 2018/8/phase } 1\end{array}$

Guy's and St Thomas' NHS

1. Guy's Hospital, Foundation Trust

2. The Oxford Transplant

Centre, Oxford, UK

University of University of California,

California, San San Francisco

Francisco

NIAID

1. University of California

at San Francisco, USA

Minnesota, USA

Guys and St

Thomas' NHS

Foundation Trust

University of

California, San

Francisco

NIAD

King's College Hospital

University of California, San Francisco

University of California, San Francisco

NIAID
2. Mayo Clinic,
June 2014/June 2019/26/phase 1 and phase 2

March 2014/February 2016/3

April 2014/March 2017/12/phase 1 and phase 2

November 2014/June 2018/16/phase 1

September 2015/ December 2018/18/ Phase 1 and phase 2

May 2016/April 2018/45 phase 1 and phase 2

July 2015/December 2019/18/phase 1
Purpose of the study

To evaluate the safety of taking a specific combination of immunosuppressant drugs after liver transplantation and the safety of receiving one of three doses of darTregs while taking this combination of immunosuppressant drugs

To test different types of Treg for safety and the promotion of kidney survival To examine in living donor renal transplant recipients the safety and feasibility of administering Treg derived from recipient PBMC stimulated with kidney donor $\mathrm{PBMC}$ in the presence of costimulatory blockade with belatacep

To asses autologous expanded polyclonal Treg as a treatment to prevent kidney transplant rejection with infusion into the patient 5 days after kidney transplant for end-stage renal failure

To evaluate the safety and tolerability of darTreg infusion for adult, de novo living donor renal transplant recipients

To examine the safety of one dose of darTreg and to see if the Treg allow the recipient of a living donor liver transplant to take less or completely stop the medications normally taken after receiving an organ transplant

To examine the feasibility, safety and efficacy of an autologous Treg product as an adjunct immunosuppressive treatment in liver transplantation

Pilot study of CD4+CD127 low/-CD25+ polyclonal Treg adoptive immunotherapy in renal transplant recipients. The aim is to test the safety of a single infusion of autologous expanded Treg

To see if polyclonal Treg or darTreg can reduce inflammation in a transplanted kidney and find out the effects of taking everolimus after polyclonal Treg or darTreg on the kidney recipient

To evaluate the safety, tolerability, and effect of 3 different doses of ex vivo-expanded autologous polyclonal Treg therapy in adults with skin (cutaneous) involvement of their lupus

NIAID, National Institute of Allergy and infectious Diseases; Treg, regulatory T cell; darTreg, donor alloantigen reactive regulatory $T$ cell. 
benefit from adjuvant supply of low-dose IL-2, which can selectively potentiate Treg function without establishing global immune activation. It is now an exciting time to conduct Treg cell therapy with manipulation of different cytokines and the microenvironment to achieve a successful and potential cure in patients with AILD.

\section{AUTHOR CONTRIBUTIONS}

All authors listed have made substantial, direct, and intellectual contribution to the work and approved it for publication. The views expressed in this paper are those of the author(s) and not

\section{REFERENCES}

1. Sakaguchi S. Naturally arising Foxp3-expressing CD25+CD4+ regulatory $\mathrm{T}$ cells in immunological tolerance to self and non-self. Nat Immunol (2005) 6:345-52. doi:10.1038/ni1178

2. Sakaguchi S, Sakaguchi N, Asano M, Itoh M, Toda M. Immunologic selftolerance maintained by activated T cells expressing IL-2 receptor alphachains (CD25). Breakdown of a single mechanism of self-tolerance causes various autoimmune diseases. J Immunol (1995) 155:1151-64.

3. Taylor PA, Lees CJ, Blazar BR. The infusion of ex vivo activated and expanded CD4(+)CD25(+) immune regulatory cells inhibits graft-versus-host disease lethality. Blood (2002) 99:3493-9. doi:10.1182/blood.V99.10.3493

4. Hori S, Nomura T, Sakaguchi S. Control of regulatory T cell development by the transcription factor Foxp3. Science (2003) 299:1057-61. doi:10.1126/ science. 1079490

5. Fontenot JD, Gavin MA, Rudensky AY. Foxp3 programs the development and function of CD4+CD25+ regulatory T cells. Nat Immunol (2003) 4:330-6. doi:10.1038/ni904

6. Seddiki N, Santner-Nanan B, Martinson J, Zaunders J, Sasson S, Landay A, et al. Expression of interleukin (IL)-2 and IL-7 receptors discriminates between human regulatory and activated T cells. J Exp Med (2006) 203:1693-700. doi:10.1084/jem.20060468

7. Liu W, Putnam AL, Xu-Yu Z, Szot GL, Lee MR, Zhu S, et al. CD127 expression inversely correlates with FoxP3 and suppressive function of human CD4+ T reg cells. J Exp Med (2006) 203:1701-11. doi:10.1084/jem.20060772

8. Abbas AK, Benoist C, Bluestone JA, Campbell DJ, Ghosh S, Hori S, et al. Regulatory $\mathrm{T}$ cells: recommendations to simplify the nomenclature. Nat Immunol (2013) 14:307-8. doi:10.1038/ni.2554

9. Adams DH, Ju C, Ramaiah SK, Uetrecht J, Jaeschke H. Mechanisms of immune-mediated liver injury1. Toxicol Sci (2010) 115(2):307-21. doi:10.1093/toxsci/kfq009

10. Almeida J, Polvorosa MA, Gonzalez-Quintela A, Marcos M, Pastor I, Hernandez Cerceño ML, et al. Decreased peripheral blood CD4+/CD25+ regulatory $\mathrm{T}$ cells in patients with alcoholic hepatitis. Alcohol Clin Exp Res (2013) 37:1361-9. doi:10.1111/acer.12095

11. Rau M, Schilling AK, Meertens J, Hering I, Weiss J, Jurowich C, et al. Progression from nonalcoholic fatty liver to nonalcoholic steatohepatitis is marked by a higher frequency of Th17 cells in the liver and an increased Th17/ resting regulatory $\mathrm{T}$ cell ratio in peripheral blood and in the liver. J Immunol (2016) 196:97-105. doi:10.4049/jimmunol.1501175

12. Taubert R, Hardtke-Wolenski M, Noyan F, Wilms A, Baumann AK, Schlue J, et al. Intrahepatic regulatory $\mathrm{T}$ cells in autoimmune hepatitis are associated with treatment response and depleted with current therapies. J Hepatol (2014) 61(5):1106-14. doi:10.1016/j.jhep.2014.05.034

13. Peiseler M, Sebode M, Franke B, Wortmann F, Schwinge D, Quaas A, et al. FOXP3+ regulatory $\mathrm{T}$ cells in autoimmune hepatitis are fully functional and not reduced in frequency. J Hepatol (2012) 57:125-32. doi:10.1016/j. jhep.2012.02.029

14. Oo YH, Banz V, Kavanagh D, Liaskou E, Withers DR, Humphreys E, et al. CXCR3-dependent recruitment and CCR6-mediated positioning of Th-17 necessarily those of the NHS, the NIHR, or the Department of Health.

\section{FUNDING}

Dr. YO was funded by MRC Clinician Scientist Award (G1002552), Queen Elizabeth Hospital Charity, Bowel Disease Research Foundation. Dr. HJ was funded by the National Institute of Health Research Birmingham Liver Biomedical Research Unit and MRC. Ms. MB was funded by National Institute of Health Research Rare Disease Translational Research Collaborative Grant (UK-Autoimmune Hepatitis).

cells in the inflamed liver. J Hepatol (2012) 57:1044-51. doi:10.1016/j. jhep.2012.07.008

15. Chen YY, Jeffery HC, Hunter S, Bhogal R, Birtwistle J, Braitch MK, et al. Human intrahepatic Tregs are functional, require IL-2 from effector cells for survival and are susceptible to fas ligand mediated apoptosis. Hepatology (2016) 64(1):138-50. doi:10.1002/hep.28517

16. Webb GJ, Siminovitch KA, Hirschfield GM. The immunogenetics of primary biliary cirrhosis: a comprehensive review. J Autoimmun (2015) 64:42-52. doi:10.1016/j.jaut.2015.07.004

17. Lan RY, Cheng C, Lian ZX, Tsuneyama K, Yang GX, Moritoki Y, et al. Livertargeted and peripheral blood alterations of regulatory $\mathrm{T}$ cells in primary biliary cirrhosis. Hepatology (2006) 43:729-37. doi:10.1002/hep.21123

18. Adams DH, Eksteen B. Aberrant homing of mucosal $\mathrm{T}$ cells and extraintestinal manifestations of inflammatory bowel disease. Nat Rev Immunol (2006) 6:244-51. doi:10.1038/nril784

19. Adams DH, Eksteen B, Curbishley SM. Immunology of the gut and liver: a love/hate relationship. Gut (2008) 57(6):838-48. doi:10.1136/gut.2007.122168

20. Eksteen B, Grant AJ, Miles A, Curbishley SM, Lalor PF, Hübscher SG, et al. Hepatic endothelial CCL25 mediates the recruitment of CCR9+ gut-homing lymphocytes to the liver in primary sclerosing cholangitis. J Exp Med (2004) 200:1511-7. doi:10.1084/jem.20041035

21. Eksteen B, Miles A, Curbishley SM, Tselepis C, Grant AJ, Walker LS, et al. Epithelial inflammation is associated with CCL28 production and the recruitment of regulatory T cells expressing CCR10. J Immunol (2006) 177:593-603. doi:10.4049/jimmunol.177.1.593

22. Choi YS, Lee J, Lee HW, Chang DY, Sung PS, Jung MK, et al. Liver injury in acute hepatitis $\mathrm{A}$ is associated with decreased frequency of regulatory $\mathrm{T}$ cells caused by Fas-mediated apoptosis. Gut (2015) 64:1303-13. doi:10.1136/ gutjnl-2013-306213

23. Moriyama T, Guilhot S, Klopchin K, Moss B, Pinkert CA, Palmiter RD, et al. Immunobiology and pathogenesis of hepatocellular injury in hepatitis B virus transgenic mice. Science (1990) 248:361-4. doi:10.1126/science.1691527

24. Stoop JN, van der Molen RG, Baan CC, van der Laan LJ, Kuipers EJ, Kusters JG, et al. Regulatory $\mathrm{T}$ cells contribute to the impaired immune response in patients with chronic hepatitis B virus infection. Hepatology (2005) 41:771-8. doi:10.1002/hep.20649

25. Dong X, Gong Y, Zeng H, Hao Y, Wang X, Hou J, et al. Imbalance between circulating $\mathrm{CD} 4+$ regulatory $\mathrm{T}$ and conventional $\mathrm{T}$ lymphocytes in patients with HBV-related acute-on-chronic liver failure. Liver Int (2013) 33:1517-26. doi:10.1111/liv.12248

26. Claassen MA, de Knegt RJ, Janssen HL, Boonstra A. Retention of CD4+ CD25+ FoxP3+ regulatory T cells in the liver after therapy-induced hepatitis C virus eradication in humans. J Virol (2011) 85:5323-30. doi:10.1128/ JVI.02551-10

27. Fu J, Xu D, Liu Z, Shi M, Zhao P, Fu B, et al. Increased regulatory T cells correlate with CD8 T-cell impairment and poor survival in hepatocellular carcinoma patients. Gastroenterology (2007) 132:2328-39. doi:10.1053/j. gastro.2007.03.102

28. Miyara M, Yoshioka Y, Kitoh A, Shima T, Wing K, Niwa A, et al. Functional delineation and differentiation dynamics of human $\mathrm{CD} 4+\mathrm{T}$ cells expressing 
the FoxP3 transcription factor. Immunity (2009) 30:899-911. doi:10.1016/j. immuni.2009.03.019

29. Tai X, Van Laethem F, Pobezinsky L, Guinter T, Sharrow SO, Adams A, et al. Basis of CTLA-4 function in regulatory and conventional CD4(+) T cells. Blood (2012) 119:5155-63. doi:10.1182/blood-2011-11-388918

30. Qureshi OS, Zheng Y, Nakamura K, Attridge K, Manzotti C, Schmidt EM, et al. Trans-endocytosis of CD80 and CD86: a molecular basis for the cell-extrinsic function of CTLA-4. Science (2011) 332:600-3. doi:10.1126/science.1202947

31. Cobbold SP, Adams E, Farquhar CA, Nolan KF, Howie D, Lui KO, et al. Infectious tolerance via the consumption of essential amino acids and mTOR signaling. Proc Natl Acad Sci U S A (2009) 106:12055-60. doi:10.1073/ pnas. 0903919106

32. Munn DH, Sharma MD, Lee JR, Jhaver KG, Johnson TS, Keskin DB, et al. Potential regulatory function of human dendritic cells expressing indoleamine 2,3-dioxygenase. Science (2002) 297:1867-70. doi:10.1126/ science. 1073514

33. Pallotta MT, Orabona C, Volpi C, Vacca C, Belladonna ML, Bianchi R, et al. Indoleamine 2,3-dioxygenase is a signaling protein in long-term tolerance by dendritic cells. Nat Immunol (2011) 12:870-8. doi:10.1038/ni.2077

34. Oo YH, Weston CJ, Lalor PF, Curbishley SM, Withers DR, Reynolds GM, et al. Distinct roles for CCR4 and CXCR3 in the recruitment and positioning of regulatory T cells in the inflamed human liver. J Immunol (2010) 184:2886-98. doi:10.4049/jimmunol.0901216

35. Marie JC, Letterio JJ, Gavin M, Rudensky AY. TGF-betal maintains suppressor function and Foxp3 expression in CD4+CD25+ regulatory T cells. J Exp Med (2005) 201:1061-7. doi:10.1084/jem.20042276

36. Bettelli E, Carrier Y, Gao W, Korn T, Strom TB, Oukka M, et al. Reciprocal developmental pathways for the generation of pathogenic effector TH17 and regulatory T cells. Nature (2006) 441:235-8. doi:10.1038/nature04753

37. Letterio JJ, Roberts AB. Regulation of immune responses by TGF-beta. Annu Rev Immunol (1998) 16:137-61. doi:10.1146/annurev.immunol.16.1.137

38. De Bleser PJ, Niki T, Rogiers V, Geerts A. Transforming growth factor-beta gene expression in normal and fibrotic rat liver. J Hepatol (1997) 26:886-93. doi:10.1016/S0168-8278(97)80257-7

39. Worthington JJ, Czajkowska BI, Melton AC, Travis MA. Intestinal dendritic cells specialize to activate transforming growth factor-beta and induce Foxp3+ regulatory T cells via integrin alphavbeta8. Gastroenterology (2011) 141:1802-12. doi:10.1053/j.gastro.2011.06.057

40. Travis MA, Reizis B, Melton AC, Masteller E, Tang Q, Proctor JM, et al. Loss of integrin alpha(v)beta8 on dendritic cells causes autoimmunity and colitis in mice. Nature (2007) 449:361-5. doi:10.1038/nature06110

41. Grossman WJ, Verbsky JW, Barchet W, Colonna M, Atkinson JP, Ley TJ. Human $\mathrm{T}$ regulatory cells can use the perforin pathway to cause autologous target cell death. Immunity (2004) 21:589-601. doi:10.1016/j.immuni. 2004.09.002

42. Gondek DC, Lu LF, Quezada SA, Sakaguchi S, Noelle RJ. Cutting edge: contact-mediated suppression by CD4+CD25+ regulatory cells involves a granzyme B-dependent, perforin-independent mechanism. J Immunol (2005) 174:1783-6. doi:10.4049/jimmunol.174.4.1783

43. Sakaguchi S, Wing K, Onishi Y, Prieto-Martin P, Yamaguchi T. Regulatory T cells: how do they suppress immune responses? Int Immunol (2009) 21:1105-11. doi:10.1093/intimm/dxp095

44. Bopp T, Becker C, Klein M, Klein-Hessling S, Palmetshofer A, Serfling E, et al. Cyclic adenosine monophosphate is a key component of regulatory T cell-mediated suppression. J Exp Med (2007) 204:1303-10. doi:10.1084/ jem.20062129

45. Hoeppli RE, Wu D, Cook L, Levings MK. The environment of regulatory T cell biology: cytokines, metabolites, and the microbiome. Front Immunol (2015) 6:61. doi: 10.3389/fimmu.2015.00061

46. Deaglio S, Dwyer KM, Gao W, Friedman D, Usheva A, Erat A, et al. Adenosine generation catalyzed by $\mathrm{CD} 39$ and $\mathrm{CD} 73$ expressed on regulatory $\mathrm{T}$ cells mediates immune suppression. J Exp Med (2007) 204:1257-65. doi:10.1084/ jem.20062512

47. Gregori S, Goudy KS, Roncarolo MG. The cellular and molecular mechanisms of immuno-suppression by human type 1 regulatory T cells. Front Immunol (2012) 3:30. doi:10.3389/fimmu.2012.00030

48. Fontenot JD, Rasmussen JP, Gavin MA, Rudensky AY. A function for interleukin 2 in Foxp3-expressing regulatory T cells. Nat Immunol (2005) 6:1142-51. doi:10.1038/ni1263
49. Hoyer KK, Dooms H, Barron L, Abbas AK. Interleukin-2 in the development and control of inflammatory disease. Immunol Rev (2008) 226:19-28. doi:10.1111/j.1600-065X.2008.00697.x

50. Hofer T, Krichevsky O, Altan-Bonnet G. Competition for IL-2 between regulatory and effector $\mathrm{T}$ cells to chisel immune responses. Front Immunol (2012) 3:268. doi:10.3389/fimmu.2012.00268

51. Setoguchi R, Hori S, Takahashi T, Sakaguchi S. Homeostatic maintenance of natural Foxp3(+) CD25(+) CD4(+) regulatory T cells by interleukin (IL)-2 and induction of autoimmune disease by IL-2 neutralization. J Exp Med (2005) 201:723-35. doi:10.1084/jem.20041982

52. Tang Q, Adams JY, Penaranda C, Melli K, Piaggio E, Sgouroudis E, et al. Central role of defective interleukin-2 production in the triggering of islet autoimmune destruction. Immunity (2008) 28:687-97. doi:10.1016/j. immuni.2008.03.016

53. Zhou X, Kong N, Wang J, Fan H, Zou H, Horwitz D, et al. Cutting edge: alltrans retinoic acid sustains the stability and function of natural regulatory T cells in an inflammatory milieu. J Immunol (2010) 185:2675-9. doi:10.4049/ jimmunol.1000598

54. Lu L, Lan Q, Li Z, Zhou X, Gu J, Li Q, et al. Critical role of all-trans retinoic acid in stabilizing human natural regulatory $\mathrm{T}$ cells under inflammatory conditions. Proc Natl Acad Sci U S A (2014) 111:E3432-40. doi:10.1073/ pnas. 1408780111

55. Mucida D, Park Y, Kim G, Turovskaya O, Scott I, Kronenberg M, et al. Reciprocal TH17 and regulatory T cell differentiation mediated by retinoic acid. Science (2007) 317:256-60. doi:10.1126/science.1145697

56. Mucida D, Pino-Lagos K, Kim G, Nowak E, Benson MJ, Kronenberg M, et al. Retinoic acid can directly promote TGF-beta-mediated Foxp3(+) Treg cell conversion of naive T cells. Immunity (2009) 30:471-2. doi:10.1016/j. immuni.2009.03.008

57. Bakdash G, Vogelpoel LT, van Capel TM, Kapsenberg ML, de Jong EC. Retinoic acid primes human dendritic cells to induce gut-homing, IL-10producing regulatory T cells. Mucosal Immunol (2015) 8:265-78. doi:10.1038/ mi.2014.64

58. Jeffery LE, Burke F, Mura M, Zheng Y, Qureshi OS, Hewison M, et al. 1,25-Dihydroxyvitamin D3 and IL-2 combine to inhibit T cell production of inflammatory cytokines and promote development of regulatory $\mathrm{T}$ cells expressing CTLA-4 and FoxP3. J Immunol (2009) 183:5458-67. doi:10.4049/ jimmunol.0803217

59. Smith PM, Howitt MR, Panikov N, Michaud M, Gallini CA, Bohlooly-Y M, et al. The microbial metabolites, short-chain fatty acids, regulate colonic Treg cell homeostasis. Science (2013) 341:569-73. doi:10.1126/science.1241165

60. Clambey ET, McNamee EN, Westrich JA, Glover LE, Campbell EL, Jedlicka P, et al. Hypoxia-inducible factor- 1 alpha-dependent induction of FoxP3 drives regulatory T-cell abundance and function during inflammatory hypoxia of the mucosa. Proc Natl Acad Sci U S A (2012) 109:E2784-93. doi:10.1073/ pnas. 1202366109

61. Ben-Shoshan J, Maysel-Auslender S, Mor A, Keren G, George J. Hypoxia controls CD4+CD25+ regulatory T-cell homeostasis via hypoxia-inducible factor-1alpha. Eur J Immunol (2008) 38:2412-8. doi:10.1002/eji.200838318

62. Ardeshir A, Narayan NR, Méndez-Lagares G, Lu D, Rauch M, Huang Y, et al. Breast-fed and bottle-fed infant rhesus macaques develop distinct gut microbiotas and immune systems. Sci Transl Med (2014) 6:252ra120. doi:10.1126/ scitranslmed.3008791

63. Ben Yảacov A, Lichtenstein Y, Zolotarov L, Ilan Y. The gut microbiome as a target for regulatory $\mathrm{T}$ cell-based immunotherapy: induction of regulatory lymphocytes by oral administration of anti-LPS enriched colostrum alleviates immune mediated colitis. BMC Gastroenterol (2015) 15:154. doi:10.1186/ s12876-015-0388-x

64. Oo YH, Adams DH. The role of chemokines in the recruitment of lymphocytes to the liver. J Autoimmun (2010) 34:45-54. doi:10.1016/j.jaut.2009.07.011

65. Adams DH, Lloyd AR. Chemokines: leucocyte recruitment and activation cytokines. Lancet (1997) 349:490-5. doi:10.1016/S0140-6736(96)07524-1

66. Erhardt A, Wegscheid C, Claass B, Carambia A, Herkel J, Mittrücker HW, et al. CXCR3 deficiency exacerbates liver disease and abrogates tolerance in a mouse model of immune-mediated hepatitis. J Immunol (2011) 186:5284-93. doi:10.4049/jimmunol.1003750

67. Koreth J, Matsuoka K, Kim HT, McDonough SM, Bindra B, Alyea EP III, et al. Interleukin-2 and regulatory T cells in graft-versus-host disease. N Engl J Med (2011) 365:2055-66. doi:10.1056/NEJMoa1108188 
68. Matsuoka K, Koreth J, Kim HT, Bascug G, McDonough S, Kawano Y, et al. Low-dose interleukin-2 therapy restores regulatory $\mathrm{T}$ cell homeostasis in patients with chronic graft-versus-host disease. Sci Transl Med (2013) 5:179ra143. doi:10.1126/scitranslmed.3005265

69. Saadoun D, Rosenzwajg M, Joly F, Six A, Carrat F, Thibault V, et al. Regulatory T-cell responses to low-dose interleukin-2 in HCV-induced vasculitis. $N$ Engl J Med (2011) 365:2067-77. doi:10.1056/NEJMoa1105143

70. Hartemann A, Bensimon G, Payan CA, Jacqueminet S, Bourron O, Nicolas N, et al. Low-dose interleukin 2 in patients with type 1 diabetes: a phase 1/2 randomised, double-blind, placebo-controlled trial. Lancet Diabetes Endocrinol (2013) 1:295-305. doi:10.1016/S2213-8587(13)70113-X

71. Bennett CL, Christie J, Ramsdell F, Brunkow ME, Ferguson PJ, Whitesell L, et al. The immune dysregulation, polyendocrinopathy, enteropathy, $\mathrm{X}$-linked syndrome (IPEX) is caused by mutations of FOXP3. Nat Genet (2001) 27:20-1. doi:10.1038/83713

72. Strauss L, Czystowska M, Szajnik M, Mandapathil M, Whiteside TL. Differential responses of human regulatory $\mathrm{T}$ cells (Treg) and effector T cells to rapamycin. PLoS One (2009) 4:e5994. doi:10.1371/journal.pone. 0005994

73. Van YH, Lee WH, Ortiz S, Lee MH, Qin HJ, Liu CP. All-trans retinoic acid inhibits type 1 diabetes by $\mathrm{T}$ regulatory (Treg)-dependent suppression of interferon-gamma-producing T-cells without affecting Th17 cells. Diabetes (2009) 58:146-55. doi:10.2337/db08-1154

74. Sagoo P, Ali N, Garg G, Nestle FO, Lechler RI, Lombardi G. Human regulatory $\mathrm{T}$ cells with alloantigen specificity are more potent inhibitors of alloimmune skin graft damage than polyclonal regulatory T cells. Sci Transl Med (2011) 3:83ra42. doi:10.1126/scitranslmed.3002076

75. Issa F, Hester J, Goto R, Nadig SN, Goodacre TE, Wood K. Ex vivoexpanded human regulatory $\mathrm{T}$ cells prevent the rejection of skin allografts in a humanized mouse model. Transplantation (2010) 90:1321-7. doi:10.1097/ TP.0b013e3181ff8772

76. van der Net JB, Bushell A, Wood KJ, Harden PN. Regulatory T cells: first steps of clinical application in solid organ transplantation. Transpl Int (2016) 29:3-11. doi: $10.1111 /$ tri. 12608

77. Issa $\mathrm{F}$, Wood $\mathrm{KJ}$. CD4+ regulatory $\mathrm{T}$ cells in solid organ transplantation. Curr Opin Organ Transplant (2010) 15:757-64. doi:10.1097/MOT. 0b013e32834017ae

78. Tang Q, Bluestone JA, Kang SM. CD4(+)Foxp3(+) regulatory T cell therapy in transplantation. J Mol Cell Biol (2012) 4:11-21. doi:10.1093/jmcb/mjr047

79. Oo YH, Sakaguchi S. Regulatory T-cell directed therapies in liver diseases. J Hepatol (2013) 59:1127-34. doi:10.1016/j.jhep.2013.05.034

80. Trzonkowski P, Bieniaszewska M, Juścińska J, Dobyszuk A, Krzystyniak A, Marek N, et al. First-in-man clinical results of the treatment of patients with graft versus host disease with human ex vivo expanded CD4+CD25+ CD127 - T regulatory cells. Clin Immunol (2009) 133:22-6. doi:10.1016/j.clim. 2009.06.001

81. Di Ianni M, Falzetti F, Carotti A, Terenzi A, Castellino F, Bonifacio E, et al. Tregs prevent GVHD and promote immune reconstitution in HLA-haploidentical transplantation. Blood (2011) 117:3921-8. doi:10.1182/blood-2010-10-311894

82. Brunstein CG, Miller JS, Cao Q, McKenna DH, Hippen KL, Curtsinger J, et al. Infusion of ex vivo expanded T regulatory cells in adults transplanted with umbilical cord blood: safety profile and detection kinetics. Blood (2011) 117:1061-70. doi:10.1182/blood-2010-07-293795

83. Todo S, Yamashita K, Goto R, Zaitsu M, Nagatsu A, Oura T, et al. A pilot study of operational tolerance with a regulatory $\mathrm{T}$ cell-based cell therapy in living donor liver transplantation. Hepatology (2016) 64(2):632-43. doi:10.1002/ hep. 28459
84. Benítez C, Londoño MC, Miquel R, Manzia TM, Abraldes JG, Lozano JJ, et al. Prospective multicenter clinical trial of immunosuppressive drug withdrawal in stable adult liver transplant recipients. Hepatology (2013) 58:1824-35. doi: $10.1002 /$ hep. 26426

85. Sebode M, Peiseler M, Franke B, Schwinge D, Schoknecht T, Wortmann F, et al. Reduced FOXP3(+) regulatory $\mathrm{T}$ cells in patients with primary sclerosing cholangitis are associated with IL2RA gene polymorphisms. J Hepatol (2014) 60:1010-6. doi:10.1016/j.jhep.2013.12.027

86. Desreumaux P, Foussat A, Allez M, Beaugerie L, Hébuterne X, Bouhnik Y, et al. Safety and efficacy of antigen-specific regulatory T-cell therapy for patients with refractory Crohn's disease. Gastroenterology (2012) 143:e1201-2. doi:10.1053/j.gastro.2012.07.116

87. Himmel ME, Yao Y, Orban PC, Steiner TS, Levings MK. Regulatory T-cell therapy for inflammatory bowel disease: more questions than answers. Immunology (2012) 136:115-22. doi:10.1111/j.1365-2567.2012.03572.x

88. Esensten JH, Wofsy D, Bluestone JA. Regulatory T cells as therapeutic targets in rheumatoid arthritis. Nat Rev Rheumatol (2009) 5:560-5. doi:10.1038/ nrrheum.2009.183

89. Chavele KM, Ehrenstein MR. Regulatory T-cells in systemic lupus erythematosus and rheumatoid arthritis. FEBS Lett (2011) 585:3603-10. doi:10.1016/j. febslet.2011.07.043

90. Marek-Trzonkowska N, Mysliwiec M, Dobyszuk A, Grabowska M, Techmanska I, Juscinska J, et al. Administration of CD4+CD25highCD127 regulatory $\mathrm{T}$ cells preserves beta-cell function in type 1 diabetes in children. Diabetes Care (2012) 35:1817-20. doi:10.2337/dc12-0038

91. Bluestone JA, Buckner JH, Fitch M, Gitelman SE, Gupta S, Hellerstein MK, et al. Type 1 diabetes immunotherapy using polyclonal regulatory T cells. Sci Transl Med (2015) 7:315ra189. doi:10.1126/scitranslmed.aad4134

92. Noyan F, Lee YS, Hardtke-Wolenski M, Knoefel AK, Taubert R, Baron U, et al. Donor-specific regulatory $\mathrm{T}$ cells generated on donor $\mathrm{B}$ cells are superior to CD4+CD25high cells in controlling alloimmune responses in humanized mice. Transplant Proc (2013) 45:1832-7. doi:10.1016/j.transproceed. 2013.01.073

93. Cheraï M, Hamel Y, Baillou C, Touil S, Guillot-Delost M, Charlotte F, et al. Generation of human alloantigen-specific regulatory $\mathrm{T}$ cells under good manufacturing practice-compliant conditions for cell therapy. Cell Transplant (2015) 24:2527-40. doi:10.3727/096368914X683566

94. Longhi MS, Hussain MJ, Kwok WW, Mieli-Vergani G, Ma Y, Vergani D. Autoantigen-specific regulatory $\mathrm{T}$ cells, a potential tool for immune-tolerance reconstitution in type-2 autoimmune hepatitis. Hepatology (2011) 53:536-47. doi:10.1002/hep.24039

95. Hu CJ, Song G, Huang W, Liu GZ, Deng CW, Zeng HP, et al. Identification of new autoantigens for primary biliary cirrhosis using human proteome microarrays. Mol Cell Proteomics (2012) 11:669-80. doi:10.1074/mcp. M111.015529

Conflict of Interest Statement: The authors declare that the research was conducted in the absence of any commercial or financial relationships that could be construed as a potential conflict of interest.

Copyright (c) 2016 Jeffery, Braitch, Brown and Oo. This is an open-access article distributed under the terms of the Creative Commons Attribution License (CC BY). The use, distribution or reproduction in other forums is permitted, provided the original author(s) or licensor are credited and that the original publication in this journal is cited, in accordance with accepted academic practice. No use, distribution or reproduction is permitted which does not comply with these terms. 